\title{
Odor conditioning with morphine: Conditioned preference, aversion, and analgesia
}

\author{
CHRISTOPHER K. RANDALL, PHILIPP J. KRAEMER, JOANNE M. VALONE, \\ and MICHAEL T. BARDO \\ University of Kentucky, Lexington, Kentucky
}

\begin{abstract}
The dose-dependent effects of morphine on odor conditioning in rats were examined in two experiments. Subjects received one odor paired with either a low dose of morphine $(0.5 \mathrm{mg} / \mathrm{kg}$; Experiment $1 \mathrm{~A})$ or a high dose of morphine $(10.0 \mathrm{mg} / \mathrm{kg}$; Experiment $1 \mathrm{~B})$, alternating with another odor paired with saline. In Experiment 1A, subjects spent significantly more time over the morphine-paired odor than over the saline-paired odor in a spatial-odor preference test (odor preference). In Experiment 1B, subjects spent significantly less time over the morphine-paired odor than over the saline-paired odor (odor aversion). In Experiment 2, pairing an odor with a high dose of morphine $(10.0 \mathrm{mg} / \mathrm{kg})$ produced a conditioned analgesic response, measured by paw-lick latency. These studies demonstrate that an odor may serve as an effective stimulus to which the motivational and analgesic effects of morphine can be conditioned.
\end{abstract}

Morphine is a multifaceted unconditioned stimulus (US), as is evidenced by its appetitive, aversive, and analgesic properties. In rats, the appetitive property of morphine has been demonstrated directly in the self-administration paradigm (Collins, Weeks, Cooper, Good, \& Russell, 1984; Weeks, 1962), as well as indirectly in the conditioned place preference (CPP) paradigm (Bardo, Miller, \& Neisewander, 1984; Blander, Hunt, Blair, \& Amit, 1984; Carr, Fibiger, \& Phillips, 1989; Katz \& Gormezano, 1979; Sherman, Pickman, Rice, Liebeskind, \& Holman, 1980). With CPP, a distinct context serves as the conditioned stimulus (CS) paired with morphine as the US. After repeated CS-US pairings, animals demonstrate a preference for the morphine-paired context.

The aversive effects of morphine have been made apparent in numerous studies with the use of the conditioned taste aversion paradigm (Bardo, Miller, \& Risner, 1984; Cappell \& LeBlanc, 1973; Farber, Gowman, \& Reid, 1976; Riley, Jacobs, \& LoLordo, 1978). In these studies, injections of a morphine US following ingestion of a novel taste CS has resulted in a marked decrease in the subjects' subsequent consumption of that taste. Interestingly, this aversive effect only appears with high doses of morphine. In contrast, when a taste is conditioned with a low dose of morphine, animals actually demonstrate a postconditioning increase in consumption of the taste CS (Lett \& Grant, 1989; Mucha \& Herz, 1985, 1986).

Conditioning of the analgesic properties of morphine has also been investigated extensively. In particular, morphine-induced analgesia has been studied primarily

This research was supported in part by National Institutes of Health Grant 2 S07 RR07114-21 to P.J.K. and National Institute on Drug Abuse Grant DA07746 to M.T.B. The authors wish to thank R. Hardesty and D. Graves for their assistance in conducting Experiment 1, as well as two anonymous reviewers for their comments on an earlier draft of this paper. All correspondence should be addressed to C. K. Randall, Department of Psychology, University of Kentucky, Lexington, KY 40506-0044. by researchers interested in the role of contextual CSs in drug tolerance. Siegel $(1975,1976,1977)$ proposed that tolerance to the unconditioned analgesic properties of morphine reflects an associative process that does not occur simply because of drug exposure. According to this theory, repeated administrations of morphine paired with a distinct context produce conditioning of a compensatory hyperalgesic response that attenuates the analgesic unconditioned response to the drug (UR). Siegel considered this process to be an explanation of drug tolerance.

More recently, however, Paletta and Wagner (1986) have hypothesized that a compensatory $C R$ may occur only in situations in which the UR is biphasic, as with morphine. Other recent theoretical formulations in the field of drug conditioning have emphasized the importance of precisely defining the US in conditioning (Eikelboom \& Stewart, 1982) and have added the notions of UShabituation and homeostasis as factors in drug tolerance (Baker \& Tiffany, 1985; Kesner \& Baker, 1981; Poulos \& Cappell, 1991).

In addition to the nature of the US, it appears as though the specific nature of the CS may be equally as important in drug conditioning. Garcia and Koelling (1966) provided the first demonstration of the cue-to-consequence phenomenon by pairing a taste and audiovisual compound CS with either footshock or an injection of $\mathrm{LiCl}$. When they tested rats separately on the two CS elements, Garcia and Koelling found that those conditioned with $\mathrm{LiCl}$ expressed a stronger aversion to the taste than to the audiovisual cues. In contrast, rats conditioned with shock expressed a stronger aversion to the audiovisual cues than to the taste. This cue-to-consequence phenomenon has been subsequently demonstrated in numerous experiments (see Domjan, 1983, for a review).

In a study that has implications for the cue-to-consequence phenomenon, Miller, Kelly, Neisewander, McCoy, and Bardo (1990) demonstrated that a gustatory cue can serve 
as an effective $\mathrm{CS}$ in conditioning both morphine-induced taste aversions and analgesia. Specifically, the experiments by Miller et al. (1990) indicated that the pairing of a gustatory CS with morphine not only results in an aversion to the taste cue, but also endows the CS with the ability to elicit an analgesic CR that mimics the UR. These results contrast with the hyperalgesic CR that has been reported when contextual CSs are paired with morphine (Krank, 1987; Krank, Hinson, \& Siegel, 1981; Siegel, 1975), and point out the need for more research to assess the capacity of different CSs to support drug conditioning.

The purpose of the present study was to assess the ability of an odor cue to serve as a CS in morphine conditioning with adult rats. Although the olfactory system is known to be anatomically and functionally prominent in rats ( $\mathrm{Al}-$ berts, 1984), there is surprisingly little information on the ability of olfactory stimuli to mediate drug conditioning. One notable exception to this is evidence that odor cues can be used to condition an appetitive reaction in neonatal rats when the cues are paired with a low dose of morphine, and an aversive reaction when they are paired with a high dose of morphine (Randall, Kraemer, Dose, Carbary, \& Bardo, 1992). At present, however, it is not clear whether such odor conditioning is unique to neonates or whether adult rats possess a similar capacity to form odormorphine associations. It is possible that adults may not readily utilize odor cues because of the ontogenetic emergence of other sensory systems, such as vision, which are not available to the neonate (Alberts, 1984). Therefore, to answer this question directly, we tested adult rats for their ability to form associations between an odor cue and appetitive, aversive, and analgesic effects of morphine.

\section{EXPERIMENT 1}

The appetitive effects of a low dose of morphine have been previously demonstrated with taste conditioning in both preweanling and adult rats (Kehoe, 1988; Lett \& Grant, 1989). Odor conditioning with a low dose of morphine has been demonstrated only in preweanling rats (Kehoe, 1988; Randall et al., 1992). The goal of Experiment $1 \mathrm{~A}$ was to produce a conditioned preference in adult rats for an artificial odor paired with a low dose of morphine $(0.5 \mathrm{mg} / \mathrm{kg})$. Experiment $1 \mathrm{~B}$, on the other hand, was designed to investigate aversive conditioning by using a high dose of morphine $(10.0 \mathrm{mg} / \mathrm{kg})$, which is known to produce taste aversions in adult rats (Lett \& Grant, $1989)$, and which exceeds the minimum dose $(2.0 \mathrm{mg} / \mathrm{kg})$ that produces taste and odor aversions in neonatal rats (Kehoe, 1988; Randall et al., 1992).

\section{Method}

Subjects. Sixteen naive Harlan Sprague-Dawley male albino rats, each weighing approximately $500 \mathrm{~g}$, served as subjects. They were individually housed in standard wire cages with ad-lib access to both rat chow and water throughout the experiment. The subjects were maintained in a climate-controlled vivarium. Testing occurred during the light phase of a 14:10-h light:dark cycle.

Apparatus. Conditioning was conducted in individual wire-mesh metal cages in a room separate from the colony room. Fresh pine shavings, on which the artificial odors were placed, were spread underneath each conditioning cage. Testing occurred in a black wooden box $(27 \times 21 \times 21 \mathrm{~cm})$ with a wire-screen floor raised $3 \mathrm{~cm}$ above the bottom of the test box. Pine shavings were placed underneath the screen floor on each side of the test chamber. Pine shavings under one side of each test chamber contained $1 \mathrm{ml}$ of orange flavor extract (Kroger brand), while the shavings on the other side contained $1 \mathrm{ml}$ of banana flavor extract (Kroger brand). A third area between the CS odor areas contained only unscented pine shavings. As many as four identical test boxes could be placed simultaneously under a ceiling-mounted videocamera. The camera provided video input for a Videomex-V (Columbus Instruments) activity monitor. This device records the movement of a user-defined object across a video monitor screen, measuring the amount of movement in each test chamber. For the purposes of this experiment, the system was used to measure the time rats spent in each of three areas of the test box, the two CS scented areas $(11 \times 21 \times 20 \mathrm{~cm}$ each) and an unscented area $(5 \times 21 \times 20 \mathrm{~cm})$.

Procedure. The subjects were individually transported to the conditioning room in a clear plastic cage lined with pine shavings. During the 8 conditioning days, odors alternated between orange (Days $1,3,5,7$ ) and banana (Days $2,4,6,8$ ), with only one odor presented each day to all subjects. For half the subjects, morphine injections were paired with orange; for the remaining half, morphine injections were paired with banana. On each conditioning day, the subjects were first placed in the conditioning cages for $30 \mathrm{~min}$ of odor exposure. Half the subjects were then given an intraperitoneal (i.p.) injection of morphine sulfate $(0.5 \mathrm{mg} / \mathrm{kg}$ in Experiment $1 \mathrm{~A}$ and $10 \mathrm{mg} / \mathrm{kg}$ in Experiment $1 \mathrm{~B}, 1 \mathrm{ml} / \mathrm{kg}$ of body weight); the remaining animals were injected with an equal volume of physiological saline. The subjects were immediately placed back into the conditioning chambers in the presence of the odor for an additional 1-h postinjection exposure. The animals were then returned to their home cages until the next day.

On the day immediately following the last conditioning trial, the subjects were given a spatial-odor preference test. The preference test consisted of two consecutive 5-min periods during which the subjects were allowed to locomote freely around the entire test chamber. The subjects were released in the center area of the box. Relative preference for. the two odors was determined by subtracting the percent time each subject spent in the side of the chamber scented with the odor paired with morphine from the percent time the subject spent in the side of the chamber scented with the odor paired with saline (difference score). In the absence of either an odor preference or an odor aversion, these difference scores should have been approximately zero. Time spent over the middle (unscented) area was not analyzed, for two principle reasons: (1) these data represent transitions between the two CS-odor scented areas, and (2) this area was physically smaller than the two odor areas. The critical alpha level for all statistical analyses was .05 .

\section{Results and Discussion}

The mean percent time spent over the $\mathrm{CS}+, \mathrm{CS}-$, and unscented middle compartment in Experiments $1 \mathrm{~A}$ and $1 \mathrm{~B}$ are presented in Table 1. The mean difference score (including standard error) for Experiment $1 \mathrm{~A}(0.5-\mathrm{mg} / \mathrm{kg}$ morphine) is presented in panel A of Figure 1. Statistical analysis of the difference scores compared to chance $(0)$ revealed that subjects spent more time over the morphinepaired odor than over the saline-paired odor $[t(7)=2.88]$. These results demonstrate that pairing an odor with a low dose of morphine $(0.5 \mathrm{mg} / \mathrm{kg})$ produces a learned preference for that odor, relative to an odor paired with saline.

The mean difference score (including standard error) for Experiment $1 \mathrm{~B}(10.0-\mathrm{mg} / \mathrm{kg}$ morphine) is presented 
Table 1

Mean Percent Time Spent Over CS +, Middle (Unscented), and CSOdor-Scented Areas in Experiments $1 \mathrm{~A}$ (Preference) and $1 B$ (Aversion)

\begin{tabular}{cccc}
\hline & \multicolumn{3}{c}{ Test Area } \\
\cline { 3 - 4 } Experiment & CS + & Middle & CS - \\
\hline 1A & 42.8 & 34.6 & 22.6 \\
IB & 20.6 & 31.6 & 47.8 \\
\hline
\end{tabular}

in panel B of Figure 1. Statistical analysis of the difference scores compared to chance (0) revealed that subjects spent less time over the odor paired with $10-\mathrm{mg} / \mathrm{kg}$ morphine than over the odor paired with saline $[r(7)=-2.92]$. These results demonstrate that pairing an odor with a high dose of morphine $(10.0 \mathrm{mg} / \mathrm{kg})$ produces an aversion to that odor, relative to an odor paired with saline.

Experiment 1 demonstrated that pairing a low dose of morphine with an odor in adult rats produces a conditioned preference for that odor, whereas pairing a high dose of morphine with an odor produces a conditioned aversion. This biphasic dose-dependent effect of morphine on odor conditioning in adult rats is analogous to the effect that has been demonstrated with neonatal rats (Randall et al., 1992).

\section{EXPERIMENT 2}

As with the appetitive and aversive properties of morphine, it may also be possible to condition morphineinduced analgesia to olfactory stimuli. Miller et al. (1990) produced a conditioned analgesia in rats following pairings of a taste $\mathrm{CS}$ with a high dose of morphine. One problem in this study, however, was that the amount of exposure to the taste CS varied across subjects because animals were given free-choice access to the CS, thus yielding individual differences in the amount of CS consumed. The odor conditioning procedure used in Experiment 1 might

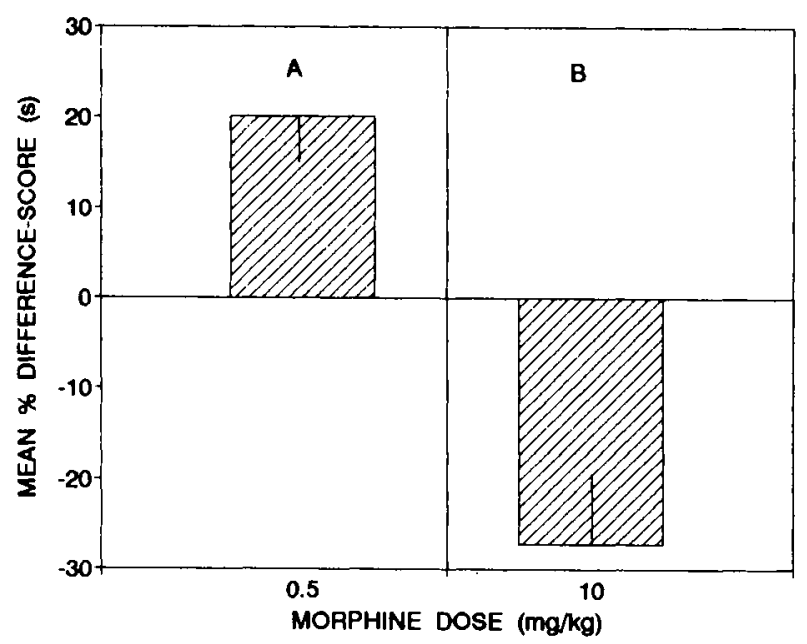

Figure 1. Mean percent difference scores in Experiment $1 \mathrm{~A}$ (panel A; odor preference) and Experiment $1 B$ (panel B; odor aversion). The bars indicate standard errors. therefore be better suited for use with an analgesia conditioning paradigm, because the amount of odor exposure, unlike taste exposure, can be experimentally controlled.

\section{Method}

Subjects. Twenty-one naive Harlan Sprague-Dawley male rats. each of which weighed approximately $450 \mathrm{~g}$, were divided equally into three groups $(n=7)$. The animals were maintained exactly as described in Experiment 1.

Apparatus. Conditioning was conducted in stainless steel cages measuring $24 \times 20 \times 18 \mathrm{~cm}$, which were located in a room separate from the colony room. Stainless steel trays placed $7.5 \mathrm{~cm}$ beneath the conditioning cages were covered with fresh pine shavings for odor presentation. Approximately $1.5 \mathrm{ml}$ of either orange or banana flavor extract (Kroger brands) were placed on the pine shavings underneath each cage. The analgesia test was conducted on a slide warming tray (Chicago Surgical \& Electric, No. 0965), covered by a clear Plexiglas chamber $(22 \times 14 \times 28 \mathrm{~cm})$ with no floor and a removable Plexiglas top. The hot plate apparatus was located in the same room as were the conditioning cages.

Procedure. Subjects were individually transported to the conditioning room in stainless steel wire cages. During 8 conditioning days, odor presentation alternated between banana (Days 1, 3, 5 . 7) and orange (Days 2, 4,6, 8), with only one odor presented each day to all the subjects. On each conditioning day, the subjects were given 15 min of exposure to the odor followed immediately by an i.p. injection of either morphine $(10 \mathrm{mg} / \mathrm{kg})$ or saline, after which they were placed back in the odor-filled conditioning chambers for an additional $30 \mathrm{~min}$. Preexposure and postinjection exposure durations were changed (from Experiments $1 \mathrm{~A}$ and $\mathrm{IB}$ ) to those used by Miller et al. (1990), because the latter durations were sufficient to produce analgesia to a taste cue and it was our intention to approximate their procedure more closely. One group received an injection of morphine during banana presentations and an injection of physiological saline on orange exposure days (Group B, $n=7$ ). The odor-morphine and odor-saline associations were reversed for a second group (Group $\mathrm{O}, n=7$ ). A third group (Group Sal, $n=7$ ) received injections of saline paired with both banana and orange odors, which served as a control for odor exposure. Immediately following each odor exposure, the subjects were placed for $1 \mathrm{~min}$ on the inactive $\left(22^{\circ} \mathrm{C}\right)$ hot plate apparatus by a second experimenter, who was unaware of group assignment, in order to allow for adaptation to the test situation.

Following the 8-day conditioning procedure, animals were tested for analgesia on Days 9 and 10. All subjects, regardless of group assignment, received saline injections on analgesia Test Days $I$ and 2 immediately after $15-\mathrm{min}$ exposure to the banana (Test Day 1) or orange (Test Day 2) odor. On test days, the subjects were placed on the active hot plate $\left(50^{\circ} \mathrm{C}\right) 30 \mathrm{~min}$ following the saline injection. Latencies to lick a hind paw were recorded by the second experimenter. Separate analyses were performed on the data from each test day, because we were concerned about the possibility of habituation to the analgesia test situation across the 2 test days.

\section{Results and Discussion}

The mean paw-lick latency (including standard error) for each group on Test Day 1 (banana odor) is presented in panel A of Figure 2. Conditioning produced a significant difference among groups on Test Day 1 , as revealed by a one-way analysis of variance ANOVA $[F(2,18)=$ 7.31]. A Newman-Keuls post hoc comparison between groups confirmed that the mean paw-lick latency for Group B was significantly longer than that for either Group O or Group Sal, which did not differ from each other. 


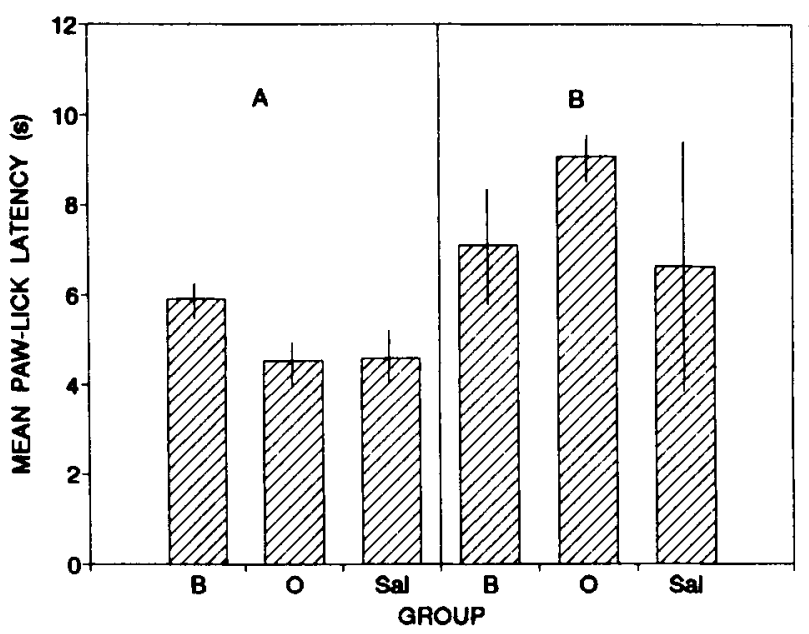

Figure 2. Mean paw-lick latencies for Group B (banana-morphine pairings), Group $O$ (orange-morphine pairings), or Group Sal (banana/orange-saline pairings) on Test Day 1 (panel A; banana odor) and Test Day 2 (panel B; orange odor). The bars indicate standard errors.

These results demonstrate an antinociceptive effect produced by exposure to the odor CS. It is clear, therefore, that an odor cue can be associated not only with motivational states induced by different doses of morphine (e.g., the appetitive and aversive effects, Experiment 1), but also with the analgesic properties of morphine.

The mean paw-lick latency (including standard error) for each group on Test Day 2 (orange odor) is presented in panel B of Figure 2. A one-way ANOVA failed to show a significant difference across the three groups on the 2 nd test day $[F(2,18)=1.10]$.

The magnitude of the analgesia observed on Test Day 1 (a 2-sec increase in latency from a 4-sec baseline) might cause some to question whether this represents "true" conditioned analgesia. For example, because subjects in Group B were experiencing a more novel situation (banana/saline/test situation) than were subjects in Group $O$ or Sal on Test Day 1, these results might be interpreted as a relative novelty effect rather than true analgesia. In other words, the novelty of the test situation might result in increased paw-lick latencies due to some behavioral mechanism (i.e., distraction) rather than conditioned analgesia. Unfortunately, the present design cannot differentiate between these two explanations. It is clear, however, that an increase in paw-lick latency does result from CS exposure, which is consistent with an antinociceptive interpretation of the data.

We must also consider the possibility that our analgesic effect is the by-product of a negative motivational effect. In other words, one might argue that the analgesia obtained here may represent a form of stress-induced analgesia, because animals were exposed to an odor paired with the aversive effect of morphine. This would suggest that analgesia is not independent of aversive conditioning.
However, such an argument is weakened by recent data (Bardo \& Valone, 1993) which demonstrate that lithium, a drug that has an aversive but not an analgesic property, fails to support a conditioned analgesic response.

The failure to find an analgesic response to the CS on Test Day 2 may be due to several factors. The variance in latencies in each group increased dramatically between Test Days 1 and 2, as is apparent in panels A and B. This is primarily due to the data from one aberrant subject in each group, and thus an increase in standard errors. The increase in paw-lick latency for Group Sal from Day 1 to Day 2 suggests that our initial concern about repeated exposures to the test situation was warranted. Other reports have shown that repeated testing on the hot plate can induce an increase in paw-lick latency indicative of analgesic conditioning processes (Greeley \& Westbrook, 1990; Rochford \& Stewart, 1987; Westbrook, Greeley, Nabke, \& Swinbourne, 1991; Westbrook, Greeley, Nabke, Swinbourne, \& Harvey, 1991). This aversive conditioning process may have obscured the morphine-induced analgesic CR on Test Day 2.

\section{GENERAL DISCUSSION}

The results of the present experiments have several important implications. First, it seems clear that odor preferences and aversions can be conditioned in adult rats by pairing an odor with either a low or a high dose of morphine, respectively. Second, evidence of odor conditioning is not restricted to the incentive motivational properties of morphine, because we also found that analgesic effects can be elicited by an odor cue previously paired with morphine. Taken together, these results suggest that odor CSs function like taste CSs, rather than like the visual-tactile cues used in most CPP studies.

The appearance of a biphasic dose-response effect of morphine, in which a low dose produced an odor preference and a high dose produced an odor aversion, is consistent with the previous use of a taste CS (Lett \& Grant, 1989; Mucha \& Herz, 1985, 1986). This indicates that adult rats respond similarly to olfactory and gustatory cues. Although evidence for the functional equivalence of odors and tastes in preweanling rats has been reported (Kraemer, Kraemer, Smoller, \& Spear, 1989), we were uncertain whether a similar tendency would emerge in adults. There is some evidence that immature rats are less likely than adults to differentiate olfactory and gustatory stimuli, which could contribute to a functional equivalence of odor and taste conditioning in the young rat (Spear, Kraemer, Molina, \& Smoller, 1988). We reasoned, therefore, that the sensory-perceptual maturity of the adult could perhaps lead to a conditioned odor preference at this age, regardless of the dose level of morphine. This hypothesis was thought to be especially plausible given that high doses of morphine typically produce CPP in adult rats (see Carr et al., 1989). In many CPP studies, places have been defined in part by salient odor cues (Carr et al., 
1989). Our results reveal, however, that adult rats, not unlike neonatal rats, express learned odor aversions when conditioned with a high dose of morphine.

The present results, therefore, raise an interesting issue with respect to CPP studies. CPP has been successfully demonstrated in rats with a range of doses of morphine that includes the dose used in Experiment 2 (Bardo, Miller, \& Neisewander, 1984; Blander et al., 1984; Katz \& Gormezano, 1979; Sherman et al., 1980). This is interesting, because in these studies, odor has typically been used as one of the place-defining cues in the CPP chamber. Thus, when conditioned as part of a contextual compound stimulus, along with visual and tactile cues, odormorphine pairings produce a preference for that location; when conditioned separately, however, our results show that odor-morphine pairings produce an aversion to that odor. Although the present results do not clarify the mechanism behind this inconsistency, it does appear that the use of nonolfactory environmental cues may be critical for demonstrating CPP with high doses of morphine. Consistent with this hypothesis, it has been shown that $10 \mathrm{mg} / \mathrm{kg}$ morphine will produce CPP, rather than an aversion, when paired with either tactile or visual cues alone (Stapelton, Lind, Merriman, Bozarth, \& Reid, 1979; Vezina \& Stewart, 1987).

Finally, it appears that olfactory and contextual cues may also produce opposing effects on pain responsivity when paired with a high dose of morphine. In the present report, an odor CS elicited an analgesic CR similar to the UR produced by morphine. Although this finding is consistent with a similar finding for a taste CS (Miller et al., 1990), it contrasts with other findings that contextual CSs elicit a hyperalgesic CR opposite to that of morphine (Krank et al., 1981; Siegel, 1975). In the latter studies, the hyperalgesic $\mathrm{CR}$ elicited by contextual cues was hypothesized to mediate tolerance to the analgesic effect of morphine. Since we did not assess tolerance directly in the present report, however, our results are not directly comparable to previous results obtained with the use of contextual CSs. Nonetheless, taken together, these findings suggest that the neural mechanism mediating morphine conditioning using odor and taste cues may be different from the neural mechanism that mediates morphine conditioning using contextual cues.

\section{REFERENCES}

AlberTs, J. R. (1984). Sensory-perceptual development in the Norway rat: A view toward comparative studies. In $R$. Kail \& N. E. Spear (Eds.), Comparative perspectives on the development of memory (pp. 65-101). Hillsdale, NJ: Erlbaum.

BAKER, T. B., \& TIFFANY, S. T. (1985). Morphine tolerance as habituation. Psychological Review, 92, 78-108.

Bardo, M. T., Miller, J. S., \& Neisewander, J. L. (1984). Conditioned place preference with morphine: Extinction of the reinforcing CR. Pharmacology, Biochemistry \& Behavior, 21, 545-549.

BARDO, M. T., Miller, J. S., Risner, M. E. (1984). Opiate receptor supersensitivity produced by chronic naloxone treatment: Dissociation of morphine-induced antinoception and conditioned taste aversion. Pharmacology, Biochemistry \& Behavior, 21, 591-597.
BARDO, M. T., \& VALONE, J. M. (1993). Morphine-conditioned analgesia using a taste cue: Dissociation of taste aversion and analgesia. Manuscript submitted for publication.

Blander, A., Hunt, T., Blair, R., A Amit, Z. (1984). Conditioned place preference: An evaluation of morphine's positive reinforcing properties. Psychopharmacology, 84, 124-127.

Cappell, H., LeBlanc, A. E. (1973). Aversive conditioning by psychoactive drugs: Effects of morphine, alcohol, and chlordiazepoxide. Psychopharmacologia, 29, 239-246.

Carr, G. D., Fibiger, H. C., Phillips, A. C. (1989). Conditioned place preference as a measure of drug reward. In J. M. Liebman \& S. J. Cooper (Eds.), The neuropharmacological basis of reward (pp. 264-319). Oxford: Oxford University Press, Clarendon Press. Collins, R. J., Weeks, J. R., CoOper, M. M., Good, P. I., \& RusSELL, R. R. (1984). Prediction of abuse liability of drugs using IV self-administration by rats. Psychopharmacology, 82, 6-13.

Domsan, M. (1983). Biological constraints on instrumental and classical conditioning: Implications for general process theory. In G. H. Bower (Ed.), The psychology of learning and motivation (Vol. 17. pp. 215-277). New York: Academic Press.

Eikelboom, R., Stewart, J. (1982). Conditioning of drug-induced physiological responses. Psychological Review, 89, 507-528.

Farber, P. D., Gorman, J. E., \& Reid, L. D. (1976). Morphine injections in the taste aversion paradigm. Physiological Psychology, 4. 365-368.

GARCIA, J., \& Koelling, R. A. (1966). Relation of cue to consequence in avoidance learning. Psychonomic Science, 4, 123-124.

Greeley, J. D., \& Westbrook, R. F. (1990). Some effects of exposure to a heat stressor upon the rat's subsequent reactions to that stressor. Quarterly Journal of Experimental Psychology, 42B, 241-265.

KatZ, R. J., Gormezano, G. (1979). A rapid inexpensive technique for assessing the reinforcing properties of opiate drugs. Pharmacology, Biochemistry \& Behavior, 11, 231-233.

KEHOE, P. (1988). Opioids, behavior, and learning in mammalian development. In E. M. Blass (Ed.), Handbook of behavioral neurobiology: Vol. 9. Developmental psychobiology and behavioral ecology (pp. 309-346). New York: Plenum.

KESNER, R. P., BAKER, T. B. (1981). A two-processs model of opiate tolerance. In J. L. McGaugh (Ed.), Endogenous peptides and learning and memory processes (pp. 479-518). San Diego: Academic Press.

Kraemer, P. J., Kraemer, E. G., Smoller, D. E., Spear, N. E. (1989). Enhancement of flavor aversion conditioning in weanling but not adult rats by prior conditioning to an odor. Psychobiology, 17, 34-42.

KRANK, M. D. (1987). Conditioned hyperalgesia depends on the pain sensitivity measure. Behavioral Neuroscience, 101, 8

Krank, M. D., Hinson, R. E., \& Siegel, S. (1981). Conditioned hyperalgesia is elicited by environmental signals of morphine. Behavioral \& Neural Biology, 32, 148-157.

LeTt, B. T., \& Grant, V. L. (1989). Conditioned taste preference produced by pairing a taste with a low dose of morphine or sufetanil. Psychopharmacology, 98, 236-239.

Miller, J. S., Kelly, K. S., Neisewander, J. L., McCoy, D. F., * BARDo, M. T. (1990). Conditioning of morphine-induced taste aversion and analgesia. Psychopharmacology, 101, 472-480.

Mucha, R. F., \& Herz, A. (1985). Motivational properties of kappa and mu opioid receptor agonists studied with place and taste preference conditioning. Psychopharmacology, 86, 274-280.

Mucha, R. F., Herz, A. (1986). Preference conditioning produced by opioid active and inactive isomers of levorphaneol and morphine in rat. Life Sciences, 38, 241-249.

Paletta, M. S., Wagner, A. R. (1986). Development of contextspecific tolerance to morphine: Support for a dual-process interpretation. Behavioral Neuroscience, 100, 611-623.

Poulos, C. X., \& CAPpell, H. (1991). Homeostatic theory of drug tolerance: A general model of physiological adaptation. Psychological Review, 98, 390-408.

Randale, C. K., Kraemer, P. J., Dose, J. M., Carbary, T. J., \& BARDO, M. T. (1992). The biphasic effect of morphine on odor conditioning in neonatal rats. Developmental Psychobiology, 25, 355-364. 
Riley, A. L., Jacobs, W. J., \& LoLordo, V. M. (1978). Morphineinduced taste aversions: A consideration of parameters. Physiological Psychology, 6, 96-100.

ROCHFORD, J., \& STEWART, J. (1987). Morphine attenuation of conditioned autoanalgesia: Implications for theories of situation-specific tolerance to morphine analgesia. Behavioral Neuroscience, 101, 690-700.

Sherman, J. E., Pickman, C., Rice, A., Liebeskind, J. C., \& HolMAN, E. W. (1980). Rewarding and aversive effects of morphine: Temporal and pharmacological properties. Pharmacology, Biochemistry \& Behavior, 13, 501-505.

Siegel, S. (1975). Evidence from rats that morphine tolerance is a learned response. Journal of Comparative and Physiological Psychology, 89, 498-506.

SIEGEL, S. (1976). Morphine analgesic tolerance: Its situation specificity supports a Pavlovian conditioning model. Science, 193, 323-325.

SIEGEL, S. (1977). Morphine tolerance as an associative process. Journal of Experimental Psychology: Animal Behavior Processes, 3, 1-13.

Spear, N. E., Kraemer, P. J., Molina, J. C., \& Smoller, D. E. (1988). Developmental change in learning and memory: Infantile disposition for unitization. In J. Delacour \& J. C. S. Levy (Eds.), Systems with learning and memory abilities (pp. 27-52). Amsterdam: North-Holland.
Stapelton, J. M., Lind, M. D., Merriman, V. J., Bozarth, M. A., \& REID, L. D. (1979). Affective consequences and subsequent effects

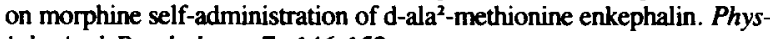
iological Psychology, 7, 146-152.

Vezina, P., \& SteWART, J. (1987). Conditioned locomotion and place preference elicited by tactile cues paired exclusively with morphine in an open field. Psychopharmacology, 91, 375-380.

WEEKS, J. R. (1962). Experimental morphine addiction: Method for automatic intravenous injections in unrestrained rats. Science, 138, 143-144.

Westbrook, R. F., Greeley, J. D., Nabke, C. P., \& Swinbourne, A. L. (1991). Aversive conditioning in the rat: Effects of a benzodiazepine and of an opioid agonist and antagonist upon conditioned hypoalgesia and fear. Journal of Experimental Psychology: Animal Behavior Processes, 17, 219-230.

Westbrook, R. F., Greeley, J. D., Nabke, C. P., Swinbourne, A. L. \& HARvEY, A. (1991). Effects of morphine and naloxone upon the reactions of rats to a heat stressor. Quarterly Journal of Experimental Psychology, 43B, 323-346.

(Manuscript received January 21, 1993; revision accepted for publication June $7,1993$. 